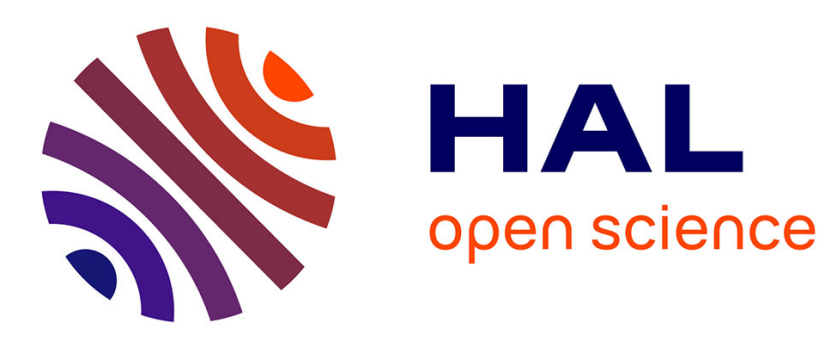

\title{
Rheology and morphology of polyester/thermoplastic flour blends
}

Florian Démé, Edith Peuvrel-Disdier, Bruno Vergnes

\section{To cite this version:}

Florian Démé, Edith Peuvrel-Disdier, Bruno Vergnes. Rheology and morphology of polyester/thermoplastic flour blends. Journal of Applied Polymer Science, 2014, 131 (10), pp.Article 40222. 10.1002/app.40222 . hal-00954544

HAL Id: hal-00954544

https://hal-mines-paristech.archives-ouvertes.fr/hal-00954544

Submitted on 13 Apr 2017

HAL is a multi-disciplinary open access archive for the deposit and dissemination of scientific research documents, whether they are published or not. The documents may come from teaching and research institutions in France or abroad, or from public or private research centers.
L'archive ouverte pluridisciplinaire HAL, est destinée au dépôt et à la diffusion de documents scientifiques de niveau recherche, publiés ou non, émanant des établissements d'enseignement et de recherche français ou étrangers, des laboratoires publics ou privés. 


\title{
Rheology and morphology of polyester/thermoplastic flour blends
}

\author{
F. Démé ${ }^{1}$ E. Peuvrel-Disdier, B. Vergnes \\ MINES ParisTech, Centre de Mise en Forme des Matériaux (CEMEF), \\ UMR CNRS 7635, BP 207, 06904 Sophia Antipolis Cedex (France)
}

${ }^{1}$ Present address : Laboratoire de Recherches et de Contrôle du Caoutchouc et des Plastiques (LRCCP), 60 rue Auber, 94408 Vitry sur Seine Cedex (France)

Corresponding author: $\quad$ E. Peuvrel-Disdier (+33) 493957589

edith.disdier@mines-paristech.fr 


\begin{abstract}
Two maize flours (standard and waxy grades) were plasticized in an internal mixer with a constant amount of water and two glycerol contents. Resulting thermoplastic flours (TPF) were characterized in dynamic oscillatory shear and creep/recovery rheometry. They displayed two different behaviors: the viscoelastic behavior of a high molecular weight polymer for the first one and a gel-like behavior for the second one. TPF were then mixed with a co-polyester (poly(butylene adipate-terephtalate), PBAT). All blends contained the same volume fractions and were prepared using the same mixing conditions. Morphology and rheological behavior of each blend were characterized. Different morphologies, ranging from cocontinuous to nodular, were observed. In fixed mixing conditions, blend morphology was shown to be governed by the rheological behavior of the starchy phase and the plasticizer content. The gel-like behavior of the second TPF seems to prevent droplets coalescence, leading to a very fine dispersion. The rheological behavior of each blend appears to be linked to both morphology and rheological behavior of the two phases.
\end{abstract}

KEY WORDS : Flour, Polyester, Glycerol, Blend, Rheology, Morphology. 


\section{Introduction}

The development of polymer/thermoplastic starch blends has recently widely increased, mainly for packaging applications [1-4]. A part of these studies is focused on synthetic polymer matrices such as polyethylene (PE) [5-10] or polyamide (PA) [11, 12]. However, the main part is devoted to bioplastics, like poly(lactic acid) (PLA) [13-17], polycaprolactone (PCL) [18-22], polybutylene adipate terephthalate (PBAT) [23-26], or other aliphatic polyesters [27-30]. In some cases, ternary systems were also studied $[16,25]$. Applications in areas such as films and bags require a fine dispersion of the starchy phase in the polymer matrix with sizes much smaller than the initial size of starch granules (5 to 20 microns). Indeed, the usual thickness of plastic films is around ten micrometers. To reach this level of dispersion, it is necessary to destroy the native starch structure, either by fragmentation or by melting and dispersion. The second method is the most used. In this case, thermomechanical processing and plasticization of the starch phase is mandatory before mixing it with the polymer matrix.

The morphology of a polymer blend depends on the rheological properties of components (viscosity ratio and elasticity ratio), volume fractions and interfacial tension [31, 32]. To reduce the interfacial tension, it is usual to add compatibilizers [7, 11, 12, 14, 22, 25].

Starch is composed of two polymer chains (amylose and amylopectin), both based on D-glucose units, and minor components such as lipids and traces of minerals [33]. Amylose is a linear chain whereas amylopectin has a highly branched structure. The rheological behavior of thermoplastic starches is more complex than the one of a classical polymer [34-38]. It depends on the starch botanical origin (more precisely the ratio amylose/amylopectin), eventual chemical modifications like esterification, amount and type of plasticizers, and thermomechanical treatment undergone by the starchy phase during processing. Starch thermal transitions and phase transformations are also more complex than those of synthetic polymers. There are two main types of crystallinity for native starch. Three others, formed by amylose/lipid or amylose/glycerol complexes, appear during cooling, after the destruction of the native crystallinity during the process $[39,40]$ and remain stable at high temperature. Therefore, to avoid parasitic crystallization problems, it is usual to plasticize starch in a first processing step and then to mix it with the polymer phase, without intermediate cooling.

Flour contains proteins in addition to starch. Its use instead of starch for preparing bioplastic blends is more seldom. Therefore, the aim of the present work is to characterize the behavior of two different thermoplastic flours (TPF) during their mixing with a PBAT matrix. TPF and blends were prepared in an internal batch mixer. The effect of plasticizer amount was also studied through the comparison of two 
formulations. For a better understanding of the morphology and the rheological behavior of the blends, a special attention was paid to the rheological characterization of TPF.

\section{Materials and methods}

\subsection{Materials}

Two maize flour types were kindly provided by the company ULICE (Riom, France): a waxy maize flour (called flour A in the following) and a standard maize flour (called flour B). They differ essentially by their amylose/amylopectin ratio. The standard grade (flour B) contains $70 \%$ of amylose and $30 \%$ of amylopectin whereas the waxy grade (flour A) only contains amylopectin. Beside starch, flours also contain proteins, lipids and some minerals in small quantities (less than 1\%).

Glycerol was chosen as a plasticizer. Two contents were selected: $15 \mathrm{wt} \%$ and $30 \mathrm{wt} \%$. These contents were based on the total weight of the TPF formula: glycerol + water + flour. Indeed, to facilitate processing, water was also added to reach, for all formulations, a total water content of $20 \mathrm{wt} \%$ (including water initially present in the flour).

The polybutylene adipate terephthalate (PBAT) (kindly provided by ULICE) is a semi-crystalline random copolymer, with a crystallinity around 10\%. Comonomer units are butylene adipate (BA) and butylene terephthalate (BT).

\subsection{Processing}

TPF and blends were processed using an internal mixer (Haake Rheocord 600P, ThermoFischer, Karlsruhe, Germany). Flour, water and glycerol were initially mixed by hand and let at rest under controlled humidity conditions for 24 hours prior introduction in the internal mixer. Mixing parameters were kept constant for all experiments: chamber temperature $=125^{\circ} \mathrm{C}$, filling ratio $=70 \%$, rotation speed $=175 \mathrm{rpm}$ and mixing time $=8 \mathrm{~min}$. After this treatment, part of the flour was removed for further analyses and the remaining part was blended with PBAT, in the same mixing conditions. The weight ratio PBAT/TPF was kept constant, PBAT forming the major phase. The exact PBAT/TPF ratio could not be indicated for confidentiality reasons, but is in the range $60-80 \mathrm{wt} \%$ for the PBAT phase and $40-20 \mathrm{wt} \%$ for the TPF.

For sake of simplicity, TPF with flour A and 30wt\% glycerol content will be denoted TPF A30 and the corresponding PBAT/TPF blend will be called A30 blend. Similar notations will be used for the other products. 


\subsection{Characterization}

TPF samples were quenched in liquid nitrogen and cryo-fractures were observed by scanning electron microscopy (SEM) using a Philips XL30 ESEM, with an accelerating voltage of $15 \mathrm{keV}$ in backscattered-electron mode. These pictures, made under a low vacuum ( 0.1 to $1 \mathrm{mPa}$ ), were intended to characterize the starch plasticization state.

Cryo-fractured TPF/PBAT blend surfaces were treated to dissolve either the starchy or the PBAT phase: attack in $1 \mathrm{~N}$ sulfuric acid for $3 \mathrm{~h}$ under magnetic stirring to dissolve the starchy phase, or dissolution of the PBAT phase in a 50/50 acetonitrile/chloroform mixture for $3 \mathrm{~h}$ at $50^{\circ} \mathrm{C}$ followed by centrifugation to collect the starchy phase. Samples were then metallized by vacuum plasma deposition of Au-Pd alloys before SEM observations.

Dynamic rheological behavior of PBAT, TPF and blends was characterized on a strain controlled rheometer (ARES, TA Instruments). Measurements were carried out with parallel plates of $25 \mathrm{~mm}$ diameter and a $1.5 \mathrm{~mm}$ gap. Samples were obtained by compression molding for $10 \mathrm{~min}$ at $20 \mathrm{MPa}$ and $150^{\circ} \mathrm{C}$, followed by cooling under pressure. Sample edges were coated with a thin film of silicone oil to limit water losses during the measurements. Striated plates were used to prevent wall slippage.

Creep/recovery measurements with a stress controlled rheometer (Stresstech, Reologica) were also performed with the same protocol.

\section{Experimental results}

\subsection{TPF characterization}

The specific mechanical energy (SME) provided during the TPF plasticization process was calculated from the time integration of the mixer torque. SME values and final product temperatures are reported in Table 1 for the different TPF (same mixing conditions). SME values are different for the two flours and mainly depend on plasticizer amount. SME value for TPF with the lowest glycerol content (15 wt\%) is indeed three times larger than for the one with the highest content (30 wt\%). This is valid for both flour types. SME values for the standard flour grade TPF B are in all cases higher than for the waxy flour grade TPF A, indicating a more viscous material. This higher viscosity also leads to a higher overheating: compared to the chamber temperature $\left(125^{\circ} \mathrm{C}\right)$, product temperatures up to $152^{\circ} \mathrm{C}$ were reached in $\mathrm{TPF}$ B15 after 8 minutes compared to $130-132^{\circ} \mathrm{C}$ for all other samples. SEM pictures (not shown here) indicate that the presence of residual granules (or fragments) is fairly low for both flours, even though TPF B shows a little more residual particles. 
Before characterizing TPF rheological behavior, their thermal stability was evaluated using time sweep tests at $1 \mathrm{rad} / \mathrm{s}$ and $150^{\circ} \mathrm{C}$ in the linear viscoelastic domain (1\% strain). We can see in Fig. 1.a that TPF storage modulus $G^{\prime}$ increased with time, even though TPF B was more stable than TPF A. As expected from torque measurements in the mixer, we can also remark that TPF B (standard grade) is more viscous than TPF A (waxy grade). Time evolution can be due to a loss of plasticizer during the measurements. To check this point, mass losses were measured after 48 hours at $130{ }^{\circ} \mathrm{C}$, on samples taken just after mixing and then after one hour at $150^{\circ} \mathrm{C}$ in the rheometer. We can see in Table 2 that mass losses vary from 8 to $23 \%$ after mixing and from 3 to $18 \%$ after rheological measurements. It thus confirms that, despite the silicon oil, part of the volatiles is evaporated during these measurements. Complementary measurements of glycerol content (performed at ENSCCF, Clermont-Ferrand, France) showed that mass losses are mainly due to water for temperatures below $200^{\circ} \mathrm{C}$. Consequently, we consider that the measured losses correspond to the amount of water present in the samples at the beginning and at the end of the thermal stability tests. It means that around 3 to $4 \mathrm{wt} \%$ of water was evaporated for TPF B in comparison with 12 to $15 \mathrm{wt} \%$ for TPF A. The greater stability of the TPF B15 is thus probably due to its low water content after processing (Table 2). Even though an equivalent water amount was initially introduced in flours A and B, TPF B15 was subjected to a much larger overheating than TPF A15 (see Table 1), leading to higher water loss. In the case of $30 \mathrm{wt} \%$ glycerol content, the overheating was low and similar for both flours, resulting in similar water losses. However, TPF A30 lost much more water during the rheological test, indicating that water appears to be less bonded to the standard flour grade A than to the waxy flour grade $\mathrm{B}$ at the same temperature.

The linear viscoelastic domain was determined for the different samples (Fig. 1.b). It is different for each TPF. The linear domain is much smaller for TPF B than for TPF A. Moreover, whatever the flour, it decreases when increasing the glycerol content. The critical strain is 1.6, 4.1, 22.2 and more than 100\%, for TPF B30, TPF B15, TPF A30, and TPF A15, respectively. This difference can be explained by the difference in rheological behavior between the two TPF.

Fig. 2 presents the viscoelastic data ( $G^{\prime}, G^{\prime}$ and complex viscosity $\eta^{*}$ versus frequency) for TPF A30 and TPF B30 at $150^{\circ} \mathrm{C}$ (similar results were obtained for TPF with $15 \mathrm{wt} \%$ glycerol but with higher values). TPF A30 shows a quasi-superposition of both modules over several decades, which is characteristic of a polymer melt of very high molecular weight with a branched structure [41, 42]. This behavior is consistent with the composition of the waxy flour (100\% amylopectin). The complex viscosity obeys a power law with an index of 0.46. Conversely, TPF B30 exhibits a gel-like behavior, with G' higher than $G$ ” over the whole range of frequencies, both modules being quite independent of frequency. The complex viscosity also obeys a power law, but with a very low index, close to 0.06 , confirming the 
plastic-like behavior of TPF B30. Such rheological behaviors have already been reported for TPS with similar amylose/amylopectin ratios [34, 35].

To complete the rheological characterization, creep experiments were carried out at $150^{\circ} \mathrm{C}$ (at $100 \mathrm{~Pa}$ during 480 s), followed by recovery (Fig. 3.a). TPF A30 shows a certain deformation during creep, proportional to time like for a viscoelastic fluid. However, the recovery seems non-existent. Conversely, TPF B30 is much more difficult to deform: under the same stress, the strain after $480 \mathrm{~s}$ is only 0.017 compared to 265 for TPF A30. However, by imposing a stress ramp between 0.1 and $50 \mathrm{~Pa}$, we can see in Fig. 3.b that TPF B30 can effectively be deformed, but to a smaller extent and only above a yield stress of around $1 \mathrm{~Pa}$.

The complex viscosities of the different formulations are compared on Fig. 4. As already seen, flour B leads to more viscous TPF than flour A and, for both materials, the viscosity decreases with the increase of glycerol content. All curves can be fitted by power laws, with indices of 0.41, 0.46, 0.16 and 0.06 for TPF A15, TPF A30, TPF B15 and TPF B30, respectively. The low power law index values for TPF B are coherent with the existence of a yield stress, as observed previously. The viscosity of the PBAT which will be used in the next section to prepare blends is also indicated on the same figure for sake of comparison. PBAT viscosity is lower than the ones of both TPF with $15 \mathrm{wt} \%$ glycerol. In the case of 30wt\% glycerol, depending on the frequency, the viscosity of PBAT can be higher than the ones of both TPF, or in between TPF B30 and TPF A30. We therefore expect to obtain different morphologies for the blends, depending on the glycerol content.

\subsection{TPF/PBAT blends characterization}

As for TPF, the specific mechanical energy (SME) provided to the blends during mixing and the final product temperatures were recorded. Results are presented in Table 3. PBAT having a melting temperature extending from 110 to $130^{\circ} \mathrm{C}$, the starch phase undergoes significant shear stresses at the beginning of mixing and overheating is important: for a chamber temperature of $125^{\circ} \mathrm{C}$, the final temperature of the blend can reach $142^{\circ} \mathrm{C}$ to $173^{\circ} \mathrm{C}$. This temperature increase is slightly higher for blends with TPF B, and more limited at high glycerol content. SME is generally high, between 170 and $563 \mathrm{kWh} / \mathrm{t}$. Values are more important for blends based on TPF B and on TPF with low glycerol content.

\subsubsection{TPF/PBAT blends morphology}

PBAT/TPF blend morphologies were analyzed by scanning electron microscopy. Pictures for A15, A30, B15 and B30 blends are presented in Figs. 5 and-6. A great diversity of both morphology and starchy phase size is observed. Blends realized with TPF A show a relatively coarse morphology, with a nodular 
morphology for A15 blend (spheres of several tens of microns, Fig. 5.a and 5b) and a co-continuous one for A30 blend (Fig. 5.c and 5.d). The co-continuity of A30 blend is more apparent in Fig. 5c, after dissolution of the starchy phase. Indeed, the starchy phase after PBAT extraction does not appear as continuous, because it is very brittle. Nevertheless, the very large size of the starchy domains tends to confirm this assumption. Contrary to what could be expected from the rheological behavior, blends made with TPF B show a much finer morphology, with a nodular starchy phase (Fig. 6). The nodules have a nice spherical shape. The average values of nodule dimensions measured by image analysis are summarized in Table 4.

\subsubsection{TPF/PBAT blends rheological behavior}

The thermal stability of the different TPF/PBAT blends was evaluated using time sweep tests at $1 \mathrm{rad} / \mathrm{s}$ and $150^{\circ} \mathrm{C}$ in the linear domain (1\% strain) (Fig. 7.a). The presence of the PBAT matrix does improve the thermal stability of the blend comparatively to TPF alone (Fig. 1.a). However, it does not fully prevent water evaporation during test. Blends based on TPF B are more stable as already noticed for the TPF.

The linear viscoelastic domain was determined for all the blends (Fig. 7.b). It is almost the same for the different blends: the critical strain is around $10 \%$ and does not depend on TPF type or glycerol content.

The linear viscoelastic behavior ( $G^{\prime}, G^{\prime}$ and complex viscosity $\eta^{*}$ versus frequency) of the different blends is shown in Fig. 8. Blend B15 presents a classical viscoelastic behavior, with $G$ ” larger than $G$ ' on the investigated range, a Newtonian plateau at low frequency and a shear thinning behavior at higher frequency. Blends A15 and A30 behave similarly with $G$ ” larger than $G$ ' over the entire frequency range and a more pronounced shear thinning behavior. A15 blend tends to show at low frequency an onset of $G$ ' plateau, associated to a low yield stress. B30 blend depicts a different behavior with G' quite superimposed with $G$ ” over the investigated frequency range. The interpretation of these results, according to the behavior of the components and the blend morphology, is discussed in the next paragraph.

\section{Discussion}

\subsection{TPF/PBAT blends morphology}

For a nodular morphology, the particle size is usually defined by the critical capillary number, which is a function of the viscosity ratio between the dispersed phase and the matrix $\eta_{d} / \eta_{m}$ [43-45]. Different expressions can be found in the literature, for simple (shear, elongation) or complex (extrusion) flow 
situations. For example, Wu [43] proposed the following empirical equation in case of blends prepared by extrusion:

$$
D=\frac{2 \sigma}{\eta_{m} \dot{\gamma}}\left(\frac{\eta_{d}}{\eta_{m}}\right)^{ \pm 0.84}
$$

where $D$ is the droplet diameter, $\sigma$ the interfacial tension and $\dot{\gamma}$ the shear rate. The exponent is positive for $\eta_{d} / \eta_{m}>1$ and negative for $\eta_{d} / \eta_{m}<1$. The ratio $\eta_{d} / \eta_{m}$ must be calculated at the shear rate and product melt temperature corresponding to the processing conditions. This empirical model was established for blends of immiscible thermoplastic polymers. It considers that the droplet size results from an equilibrium between the interfacial stress and the shear stress and takes into account the effect of the viscosity ratio. It does not consider any effect of components elasticity on the blend morphology. Therefore, our purpose in the following was just to check whether the simple consideration of the viscosity ratio and the shear stress was enough to explain the variation in droplet size of the TPF/PBAT blends. In the internal mixer, the shear rate can be estimated from the rotor speed, according to the methodology originally proposed by Bousmina et al. [46, 47]. At $175 \mathrm{rpm}$, the average shear rate is around $100 \mathrm{~s}^{-1}$. Accordingly, the viscosity ratio is equal to 0.2 and 0.4 for A30 and B30 blends, and 1.5 and 3.0 for A15 and B15 blends. If we assume that the nodule size follows Eq. (1), the smallest size should be obtained for A15 blend, the largest one for A30 blend and similar values for B15 and B30 ones. We can see in Table 4 that it is not really the case. It means that the viscosity ratio alone cannot explain the size variations of the starchy phase. Beside possible differences in the interfacial tension, the difference in rheological behavior of TPF phase is also at the origin of this size difference. Indeed, unlike TPF A, TPF B shows a gel-like behavior with a very short linear domain. This TPF is more elastic and can be deformed only under high shear stress (Fig. 3.b). Similar studies with modified highly elastic starches, mixed with PE [6] or PCL [21], indicated that the deformed starch particles form very stable fibrils due to their high elasticity. The gellike behavior of TPF B could also lead to a greater difficulty for particles to coalesce. Thus, this absence of coalescence could explain the small nodule size observed in these blends, deformation and rupture being the only possible mechanisms. In the case of TPF A, the coalescence of the droplets can be at the origin of the coarser observed morphologies. The evolution from a nodular morphology to a fibrillar one when increasing glycerol content has already been demonstrated in PE/starch blends by RodriguezGonzales et al. [6] and was explained by the viscosity ratio. In the case of TPF A, the drop in viscosity ratio when increasing the glycerol content could explain the formation of a more elongated dispersed phase which is favorable for the formation of a co-continuous morphology as observed in Fig. 7 [48]. 


\subsection{TPF/PBAT blends rheological behavior}

The rheological behavior of each blend at $150^{\circ} \mathrm{C}$ is compared to the one of its respective components (PBAT and TPF) in Fig. 9 (complex viscosity $\eta^{*}$ ) and Fig. 10 (storage modulus $G^{\prime}$ ).

Considering a blend of two immiscible polymers and applying a simple mixing rule without interfacial tension (for example, a model of Kerner [49]), one expects that the modulus or the viscosity should lie in between the component ones. However, the droplet interface (characterized by a specific time relaxation) gives rise to an additional viscoelastic contribution, characterized by a shoulder on $G^{\prime}$ curve at intermediate frequency, which can be predicted by the model of Palierne [50]).

B15 blend storage modulus and viscosity curves tend to follow the tendency of a mixing rule: B15 blend curves follow the PBAT ones but shifted to higher values. B30 blend follows also the matrix behavior but with a pronounced departure at low frequency. A15 blend follows more closely the behavior of TPF than the one of PBAT, but with values inferior to the ones of both components. It is similar for A30 blend, which exhibits a co-continuous morphology.

An attempt was made to interpret the B15 blend data using classical blend models (Kerner and Palierne). Droplet size was taken as $1 \mu \mathrm{m}$ radius (as observed by SEM) and, for Palierne model, interfacial tension was varied in the usual range, i.e. between 1 and $15 \mathrm{mN} / \mathrm{m}$. The experimental curves for the blend (Fig. 11.a) are globally fitted by the two models. However, calculations do not show any difference between the simple mixing rule and the Palierne model, whatever the range of droplet size and interfacial tension. Due to the high viscosity and elasticity of TPF B15 relatively to PBAT, inclusions do not seem to be deformed during the solicitation. For this reason, B15 blend can be considered as a suspension. A suspension model, such as a Krieger-Dougherty model for example, predicts that the suspension Newtonian viscosity is equal to the matrix one multiplied by a constant factor depending on volume fraction and close packing fraction. The viscosity curve of the suspension thus should be parallel to the matrix one in a log-log representation. This effectively corresponds to the behavior of B15 blend as shown in Fig 9.b. In Fig. 11.b, we can see that this behavior can be nicely described by the simple Einstein equation.

B30 blend (Fig. 9.d and 10.d) shows a similar rheological response, except at low frequency with the presence of an onset of $G^{\prime}$ plateau, indicating the existence of a melt yield stress. This indicates interactions between particles, eventually favored compared to B15 by the smaller particle size. This also confirms that these blends behave more like suspensions with a "solid" TPF phase than like classical blends. 
A15 and A30 blends are more close to the behavior of TPF. For these materials, TPF viscosity is closer or even lower than the PBAT one. The morphology is nodular with large nodules (A15 blend) or cocontinuous (A30 blend). Consequently, the influence of the TPF phase is more pronounced.

Anyway, it seems very difficult to propose clear explanations for these various results: the behavior of the components, together with the blend morphology, is unable to allow a correct interpretation. Moreover, it is worth pointing out that an evolution of the volume fraction of the TPS phase, via the evaporation of plasticizer during the mixing process, cannot be neglected.

\section{Conclusion}

We studied the behavior of two flours plasticized with two glycerol contents in an internal mixer and then blended with a PBAT matrix under identical conditions. The rheological study of thermoplastic flours (TPF) highlights two different behaviors. In the case of waxy grade, we observe the behavior of a high molecular weight viscoelastic polymer, and in the case of standard grade a gel-like behavior. In all cases, glycerol content only modifies the viscosity level. Water content, which decreases considerably during mixing, also influences TPF viscosity.

The study shows that TPF rheological behavior governs the blends morphology and their rheological behavior. The TPF rheological behavior is governed by the flour nature, i.e. the amylose/amylopectin ratio and the plasticizer content, in a similar way as for TPS. According to the amylose/amylopectin ratio and plasticizer content, different morphologies and sizes of the starchy phase could be obtained. The glycerol content modifies the viscosity ratio between TPF and PBAT matrix, and thus the ability of TPF particles (or droplet) to deform and break, or to coalesce to form a co-continuous phase. The development of a co-continuous structure appears to be due to the behavior, size and shape of particles rather than the viscosity ratio of the two phases. Indeed, a gel-like behavior of the dispersed phase seems to prevent the coalescence of droplets or fibrils, allowing for much finer structures. By selecting flour type, plasticizer amount and mixing conditions (not presented here), it is thus possible to obtain blends with a wide variety of morphologies and rheological properties, leading to final products with various possible applications. Using TPF in bioplastic blends may constitute interesting alternatives to TPS with an economic interest. Flour is less expensive than starch due to its simpler process of flour. Using TPF in bioplastic blends may constitute interesting alternatives to TPS with an economic interest. Flour is less expensive than starch due to its simpler process of flour. 


\section{Aknowledgements}

This study was conducted as part of the French project CEREMAT, supported by the "Cereales Vallée" cluster. We gratefully thank FUI (Fond Unique Interministériel) for financial support, project members for giving permission to publish this work and ENSCCF (Clermont-Ferrand, France) for measuring glycerol content on TPF and blends. 


\section{References}

1. Griffin, G.J.L. Polym. Deg. Stab. 1994, 45, 241-247.

2. Yu, L., Dean, K., Li, L. Prog. Polym. Sci. 2006, 31, 576-602.

3. Wang, X.L., Yang, K.K., Wang, Y.Z. J. Macromol. Sci. 2003, 43, 385-409.

4. Lu, D.R., Xiao, C.M., Xu, S.J. Express Polym. Lett. 2009, 3, 366-375.

5. St-Pierre, N., Favis, B.D., Ramsay, B.A., Ramsay, J.A., Verhoogt, H. Polymer 1997, 38, 647-655.

6. Rodriguez-Gonzalez, F.J., Ramsay, B.A., Favis, B.D. Polymer 2003, 44, 1517-1526.

7. Fu, X., Chen, X., Wen, R., He, X., Shang, X., Liao, Z., Yang, L. J. Polym. Res. 2007, 14, 297-304.

8. Walker, A.M., Tao, Y., Torkelson, J.M. Polymer 2007, 48, 1066-1074.

9. Thakore, I.M., Desai, S., Sarawade, B.D., Devi, S. Europ. Polym. J. 2005, 37, 151-160.

10. Vinhas, G.M., Moreira de Lima, S., Santos, L.A., Gomes de Andrade Lima, M.A., Bastos de Almeida, Y.M. Braz. Arch. Biol. Technol. 2007, 50, 361-370.

11. Landreau, E., Tighzert, L., Bliard, C., Berzin, F., Lacoste, C. Europ. Polym. J. 2009, 45, 2609-2618.

12. Teyssandier, F., Cassagnau, P., Gérard, J.F., Mignard, N. Europ. Polym. J. 2011, 47, 2361-2371.

13. Huneault, M.A., Li, H. Polymer 2007, 48, 270-280.

14. Jang, W.Y., Shin, B.Y., Lee, T.J., Narayan, R. J. Ind. Eng. Chem. 2007, 13, 547-464.

15. Jun C.L. J. Polym. Environ. 2000, 8, 33-37.

16. Sarazin, P., Li, G., Orts, W.J., Favis, B.D. Polymer 2008, 49, 599-609.

17. Arroyo, O.H., Huneault, M.A., Favis, B.D., Bureau, M.N. Polym. Comp. 2010, 31, 114-127.

18. Averous, L., Moro, L., Dole, P., Fringant, C. Polymer 2000, 41, 4157-4167.

19. Rosa, D.S., Guedes, C.G.F., Pedroso, A.G., Calil, M.R. Mat. Sci. Eng. C. 2004, 24, 663-670.

20. Matzinos, P., Tserki, V., Kontoyiannis, A., Panayiotou, C. Polym. Deg. Stab. 2002, 77, 17-24.

21. Li G., Favis B.D. Macromol. Chem. Phys. 2010, 211, 321-333.

22. Bossard, F., Pillin, I., Aubry, T., Grohens, Y. Polym. Eng. Sci. 2008, 48, 1862-1870.

23. Nayak, S.K. Polym. Plast. Technol. Eng. 2010, 49, 1406-1418.

24. Schwach, E., Averous, L. Polym. Int. 2004, 53, 2115-2124. 
25. Ren, J., Fu, H.Y., Ren, T.B., Yuan, W.Z. Carbohydr. Polym. 2009, 77, 576-582.

26. Nabar, Y., Raquez, J.M., Dubois, P., Narayan, R. Biomacromol. 2006, 6, 807-817.

27. Ratto, J.A., Stenhouse, P.J., Auerbach, A., Mitchell, J., Farrell, R. Polymer 1999, 40, 6777-6788.

28. Mani, R., Bhattacharya, M. Europ. Polym. J. 2001, 37, 515-526.

29. Willette, J.L., Shogren, R.L. Polymer 2002, 43, 5935-5947.

30. Vargha, V., Truter, P. Europ. Polym. J. 2005, 41, 715-726.

31. Utracki, L.A. Polymer Blends Handbook; Kluwer Academic Publishers: Dordrecht, 2002.

32. Isayev, A.I. Encyclopedia of Polymer Blends; Wiley-VCH: New York, 2010.

33. Tester, RF, Karkalas, J. In: Vandamme, E.J.; De Baets, S.; Steinbuchel, A., Eds.; Starch in biopolymers; Wiley-VCH: Weinheim, 2002, Vol. 6, pp 381-438.

34. Della Valle, G., Buléon, A., Carreau, P.J., Lavoie, P.A., Vergnes, B. J. Rheol. 1998, 42, 507-525.

35. Della Valle, G., Colonna, P., Patria, A., Vergnes, B. J. Rheol. 1996, 40, 347-362.

36. Della Valle, G., Vergnes, B., Lourdin, D. Intern. Polym. Proc. 2007, 12, 471-479.

37. Willett, J.L., Jasberg, B.K., Swanson, C.L. Polym. Eng. Sci. 1995, 35, 202-210.

38. Tajuddin, S., Xie, F.W., Nicholson, T.M., Liu, P., Halley, P.J. Carbohydr. Polym. 2011, 83, 914-919.

39. Van Soest, J.J.G., Hulleman, S.H.D., de Wit, D., Vliegenthart, J.F.G., Crystallinity in starch bioplastics. Indus. Crops. Prod. 1996, 5, 11-22.

40. Colonna, P., Mercier, C. Carbohydr. Polym.. 1983, 3, 87-108.

41. Yang, Q., Chung, T.S., Weber, M., Wollny, K. Polymer 2009, 50, 524-533.

42. McKee, M.G., Unal, S., Wilkes, G.L., Long, T.E. Prog. Polym. Sci. 2005, 30, 507-539.

43. Wu, S. Polym. Eng. Sci. 1987, 27, 335-343.

44. Grace, H.P. Chem. Eng. Comm. 1982, 14, 225-243.

45. Serpe, G., Jarrin, J., Dawans, F. Polym. Eng. Sci. 1990, 30, 553-565.

46. Bousmina, M., Ait-Kadi, A., Faisant, F.B. J. Rheol. 1999, 43, 415-433.

47. Brouillet-Fourmann, S., Carrot, C., Mignard, N., Prochazka, F. Appl. Rheol. 2000, 12, 192-200.

48. Willemse, R.C., Posthuma de Boer, A., van Dam, J., Gotsis, A. D. Polymer, 1998, 39(24),5879-5887.

49. Kerner, E.H. Proc. Phys. Soc. Lond. B 1956, LXIX, 808-813 
50. Palierne, J.F. Rheol. Acta 1990, 29(3), 204-214 


\begin{tabular}{|c|c|c|}
\cline { 2 - 3 } \multicolumn{1}{c|}{} & $\begin{array}{c}15 \mathrm{wt} \% \\
\text { glycerol }\end{array}$ & $\begin{array}{c}30 \mathrm{wt} \% \\
\text { glycerol }\end{array}$ \\
\hline Flour A & $\begin{array}{c}111 \mathrm{kWh} / \mathrm{t} \\
132^{\circ} \mathrm{C}\end{array}$ & $\begin{array}{c}38 \mathrm{kWh} / \mathrm{t} \\
130^{\circ} \mathrm{C}\end{array}$ \\
\hline Flour B & $228 \mathrm{kWh} / \mathrm{t}$ & $67 \mathrm{kWh} / \mathrm{t}$ \\
& $152^{\circ} \mathrm{C}$ & $132^{\circ} \mathrm{C}$ \\
\hline
\end{tabular}

Table 1. Specific mechanical energy (SME) during TPF processing and final product temperatures. 


\begin{tabular}{|c|c|c|c|c|}
\cline { 2 - 5 } \multicolumn{1}{c|}{} & \multicolumn{4}{|c|}{ Mass losses (\%) } \\
\cline { 2 - 5 } & TPF & TPF & TPF & TPF \\
A 15 & B 15 & A 30 & B 30 \\
\hline Before & 13.6 & 7.9 & 22.8 & 22.0 \\
\hline After & 3.1 & 5.3 & 8.0 & 17.8 \\
\hline
\end{tabular}

Table 2. Weight loss during $48 \mathrm{~h}$ at $130^{\circ} \mathrm{C}$

of samples before and after thermal stability test at $150^{\circ} \mathrm{C}$. 


\begin{tabular}{|c|c|c|}
\cline { 2 - 3 } \multicolumn{1}{c|}{} & $\begin{array}{c}15 \mathrm{wt} \% \\
\text { glycerol in } \\
\mathrm{TPF}\end{array}$ & $\begin{array}{c}30 \mathrm{wt} \% \\
\text { glycerol in } \\
\mathrm{TPF}\end{array}$ \\
\hline $\begin{array}{c}\text { TPF A / } \\
\text { PBAT } \\
\text { blend }\end{array}$ & $\begin{array}{c}461 \mathrm{kWh} / \mathrm{t} \\
169^{\circ} \mathrm{C}\end{array}$ & $\begin{array}{c}170 \mathrm{kWh} / \mathrm{t} \\
142^{\circ} \mathrm{C}\end{array}$ \\
\hline $\begin{array}{c}\text { TPF B / } \\
\text { PBAT } \\
\text { blend }\end{array}$ & $563 \mathrm{kWh} / \mathrm{t}$ & $398 \mathrm{kWh} / \mathrm{t}$ \\
$173^{\circ} \mathrm{C}$ & $164^{\circ} \mathrm{C}$ \\
\hline
\end{tabular}

Table 3. Specific mechanical energy (SME) during TPF/PBAT mixing and final product temperatures. 


\begin{tabular}{|c|c|c|c|}
\hline Blend & Morphology & $\begin{array}{c}\text { Length } \\
(\mu \mathrm{m})\end{array}$ & $\begin{array}{c}\text { Width } \\
(\mu \mathrm{m})\end{array}$ \\
\hline A15 & Nodular & 21 & 12 \\
\hline A30 & $\begin{array}{c}\text { Co- } \\
\text { continuous }\end{array}$ & $(39)$ & $(17)$ \\
\hline B15 & Nodular & 3.4 & 1.8 \\
\hline B30 & Nodular & 1.5 & 0.8 \\
\hline
\end{tabular}

Table 4. Blend morphology and medium size (length and width) of TPF nodules. 


\section{Figure captions}

Figure 1. a) Thermal stability (storage modulus $G^{\prime}$ as function of time, $1 \mathrm{rad} / \mathrm{s}, 1 \%$ strain) and b) linear domain (storage modulus $G^{\prime}$ as function of strain, $1 \mathrm{rad} / \mathrm{s}$ ) for the two TPF at $150^{\circ} \mathrm{C}$ with two plasticizer contents.

Figure 2. Viscoelastic modules $\left(G^{\prime}, G^{\prime}\right)$ and complex viscosity $\left(\eta^{*}\right)$ of TPF at 30wt\% glycerol content as function of frequency at $150^{\circ} \mathrm{C} 1 \%$ strain . a) TPF A30, b) TPF B30.

Figure 3. a) Creep-recovery tests and b) creep in stress steps for TPF A30 and TPF B30 at $150^{\circ} \mathrm{C}$.

Figure 4. Complex viscosity $\eta^{*}$ as function of frequency at $150^{\circ} \mathrm{C}, 1 \%$ strain :

० : TPF A15, $\square:$ TPF B15, • : TPF A30, $\bullet:$ TPF B30, $\Delta$ : PBAT.

Figure 5. SEM micrographs of A15 blend after extraction of a) the starchy phase, b) the PBAT and of A30 blend after extraction of c) the starchy phase, d) the PBAT.

Figure 6. SEM micrographs of B15 blend after extraction of a) the starchy phase, b) the PBAT and B30 blend after extraction of c) the starchy phase, d) the PBAT.

Figure 7. a) Thermal stability (storage modulus $G^{\prime}$ as function of time, $1 \mathrm{rad} / \mathrm{s}, 1 \%$ strain) and b) linear domain (storage modulus $G^{\prime}$ as function of strain, $1 \mathrm{rad} / \mathrm{s}$ ) for the TPF/PBAT blends at $150^{\circ} \mathrm{C}$.

Figure 8: Rheological response of the TPF / PBAT blends (storage and loss modules $G$ ' and $G$ ”, complex viscosity $\eta^{*}$ versus frequency) : a) A15 blend, b) B15 blend, c) A30 blend, d) B30 blend.

Figure 9. Complex viscosity $\eta^{*}$ as function of frequency at $150^{\circ} \mathrm{C}, 1 \%$ strain for TPF (०), PBAT (•) and TPF/PBAT blends (): a) A15, b) B15, c) A30, d) B30.

Figure 10. Storage modulus $G^{\prime}$ as function of frequency at $150^{\circ} \mathrm{C}, 1 \%$ strain for TPF $(\circ)$, PBAT $(\bullet)$ and TPF/PBAT blends (ロ): a) A15, b) B15, c) A30, d) B30.

Figure 11. Comparison between model predictions and experimental measurements for B15 blend: a) storage modulus, b) viscosity. Symbols are experimental values. Lines are obtained with Palierne (-), Kerner (----) and Einstein (.....) models 

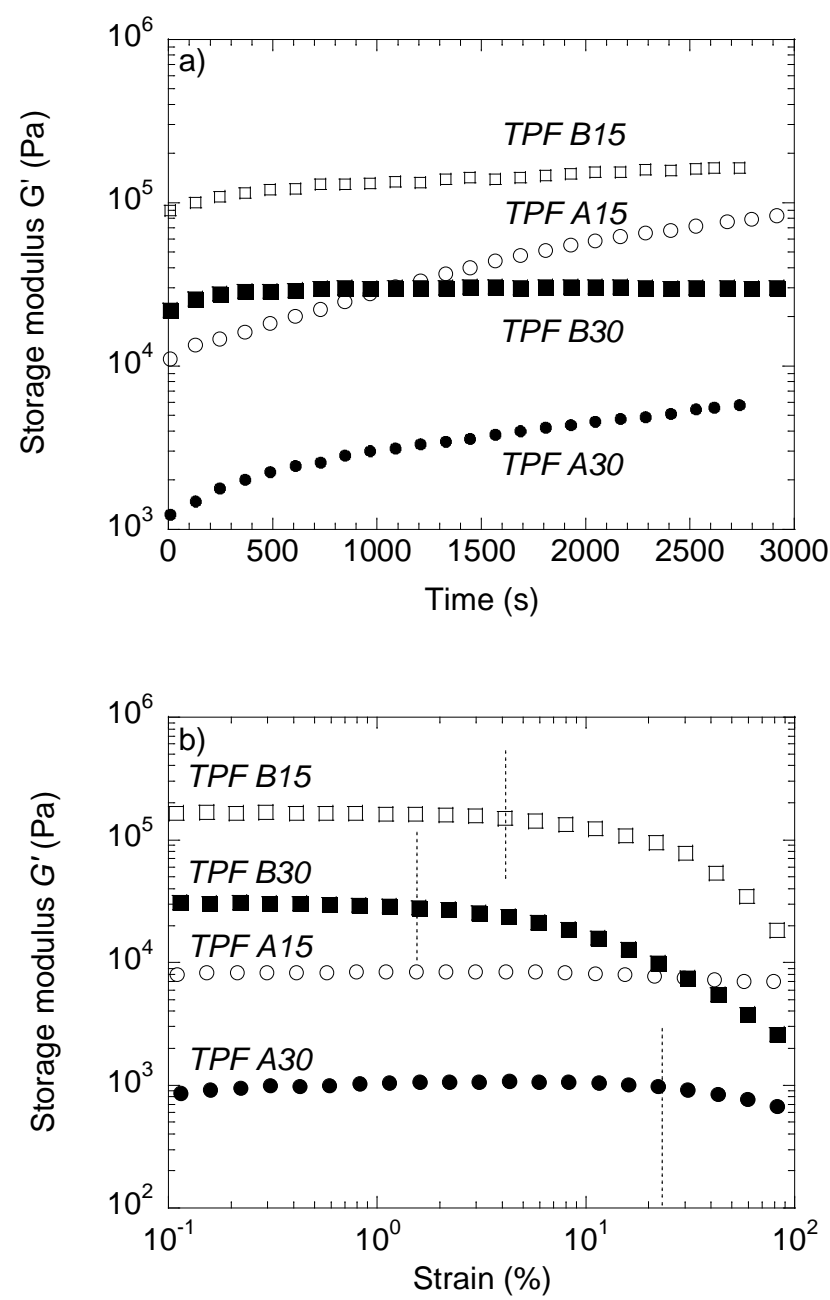

Figure 1. Démé et al. 

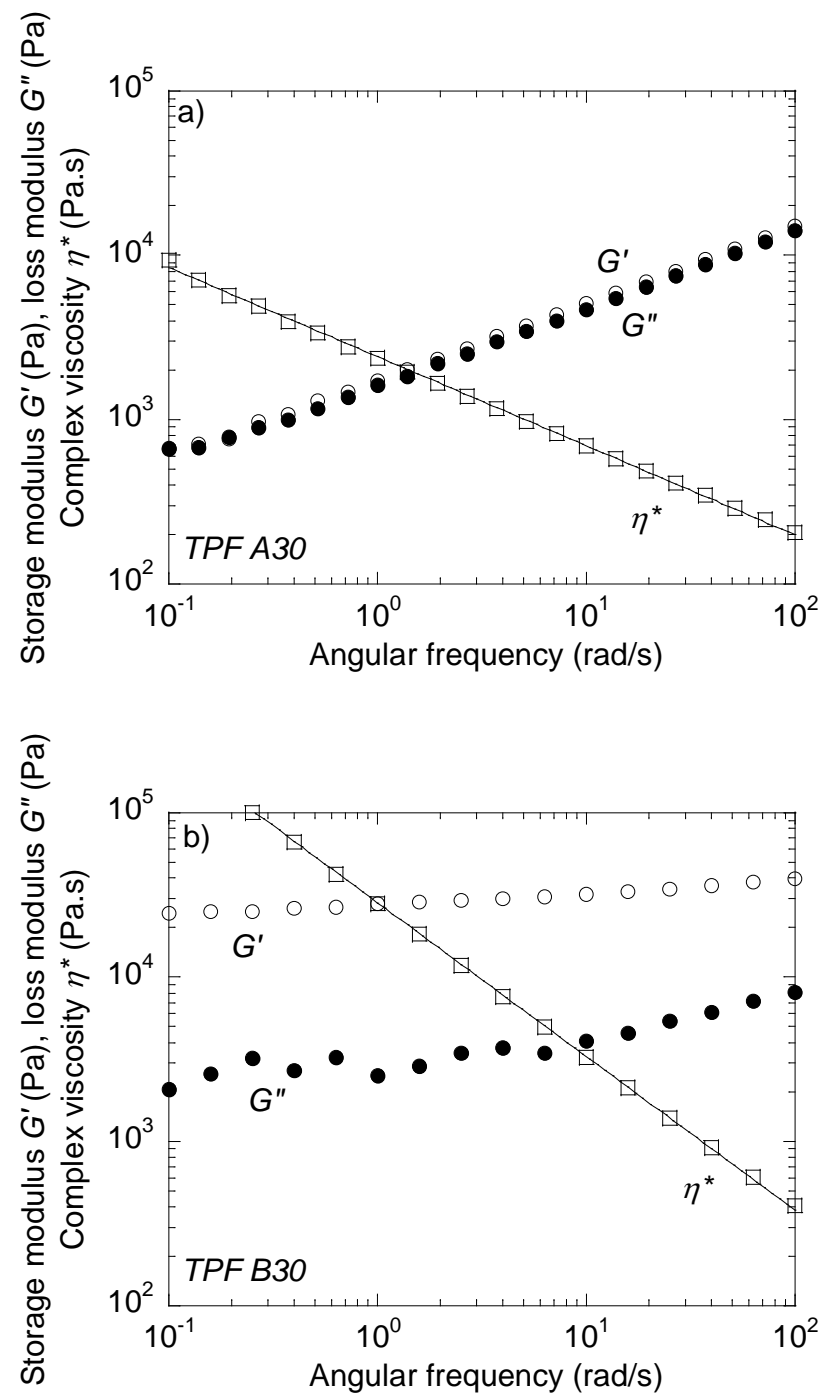

Figure 2. Démé et al. 

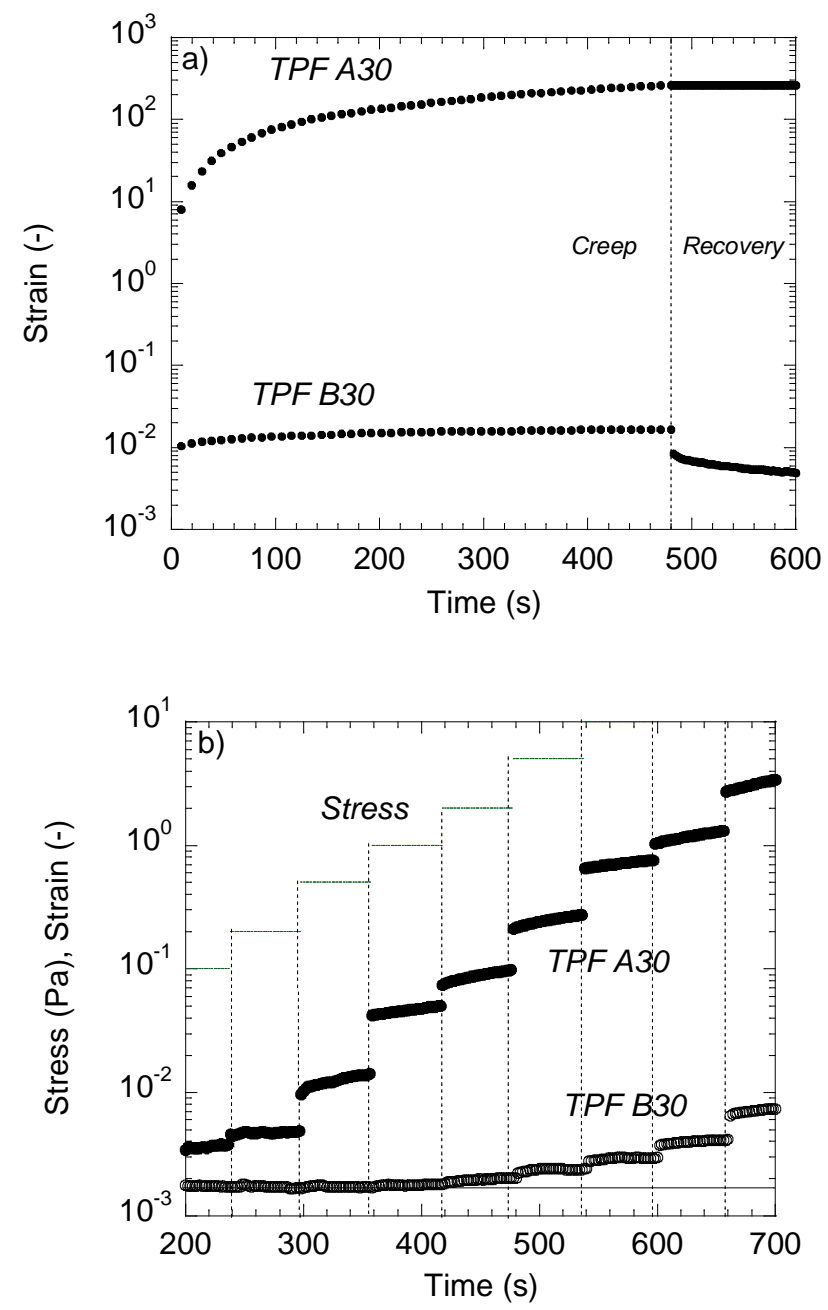

Figure 3. Démé et al. 


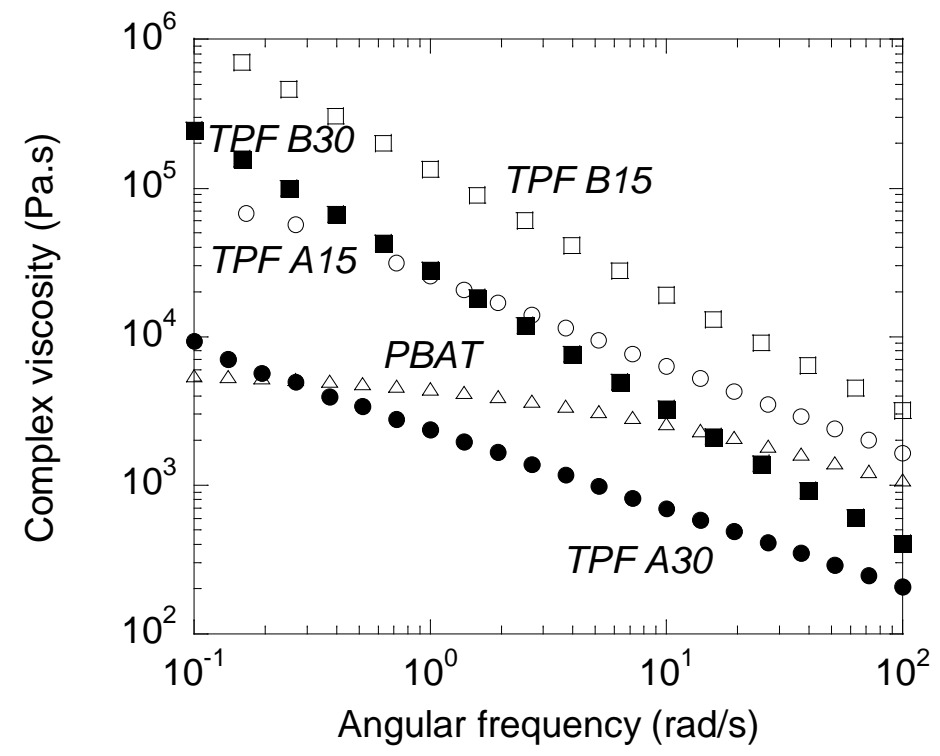

Figure 4. Démé et al. 

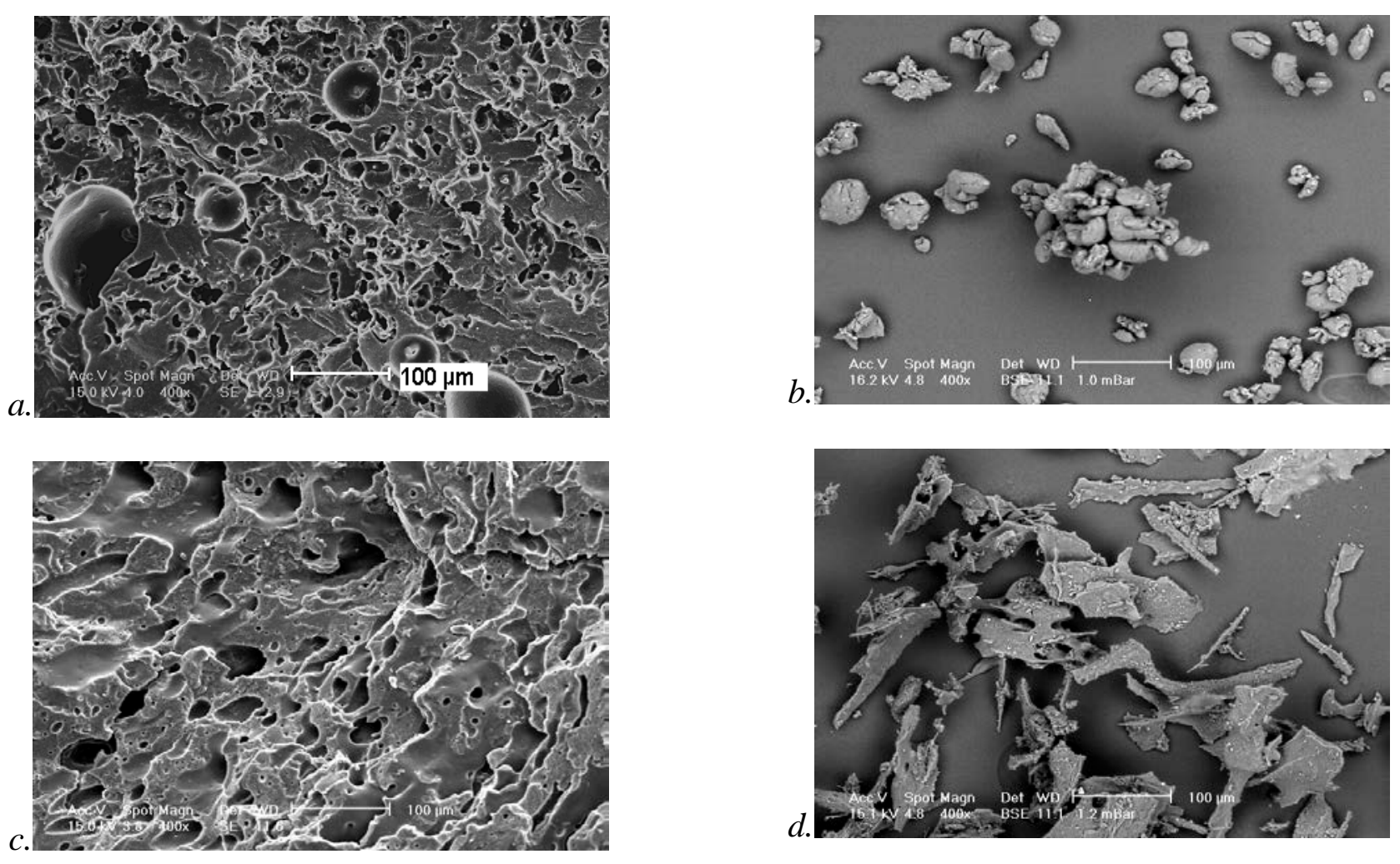

Figure 5. Démé et al. 

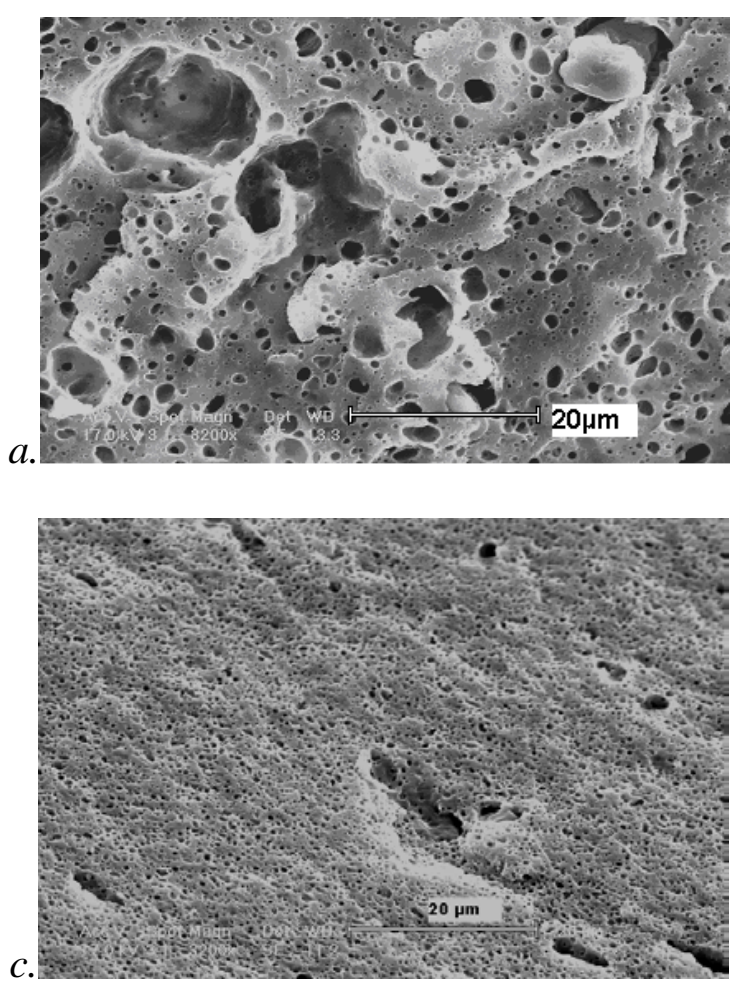
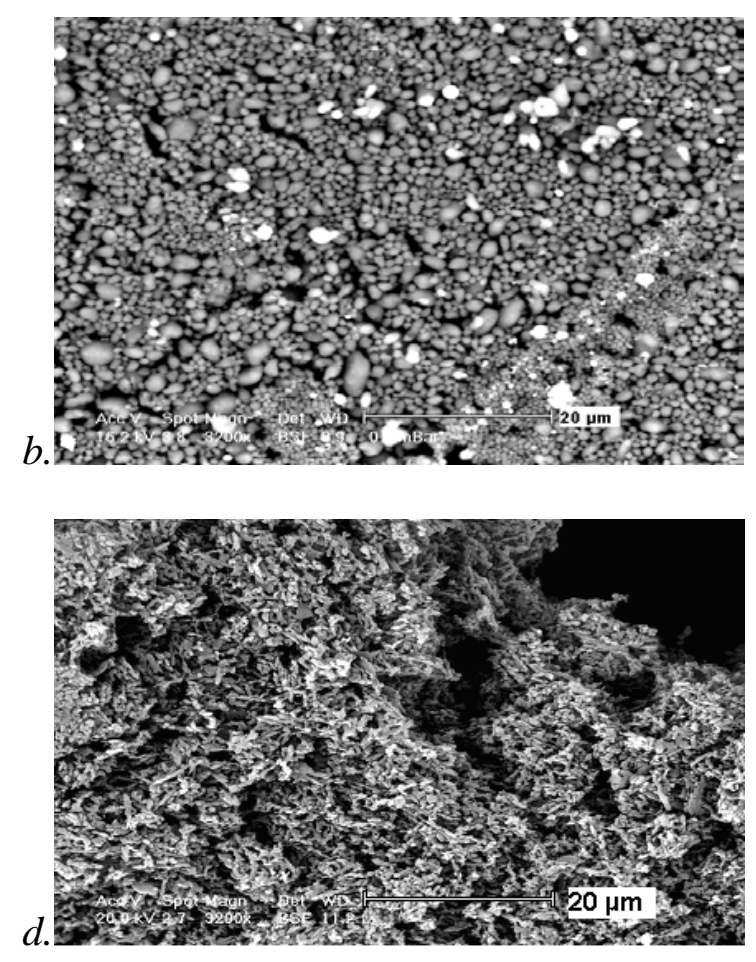

Figure 6. Démé et al. 

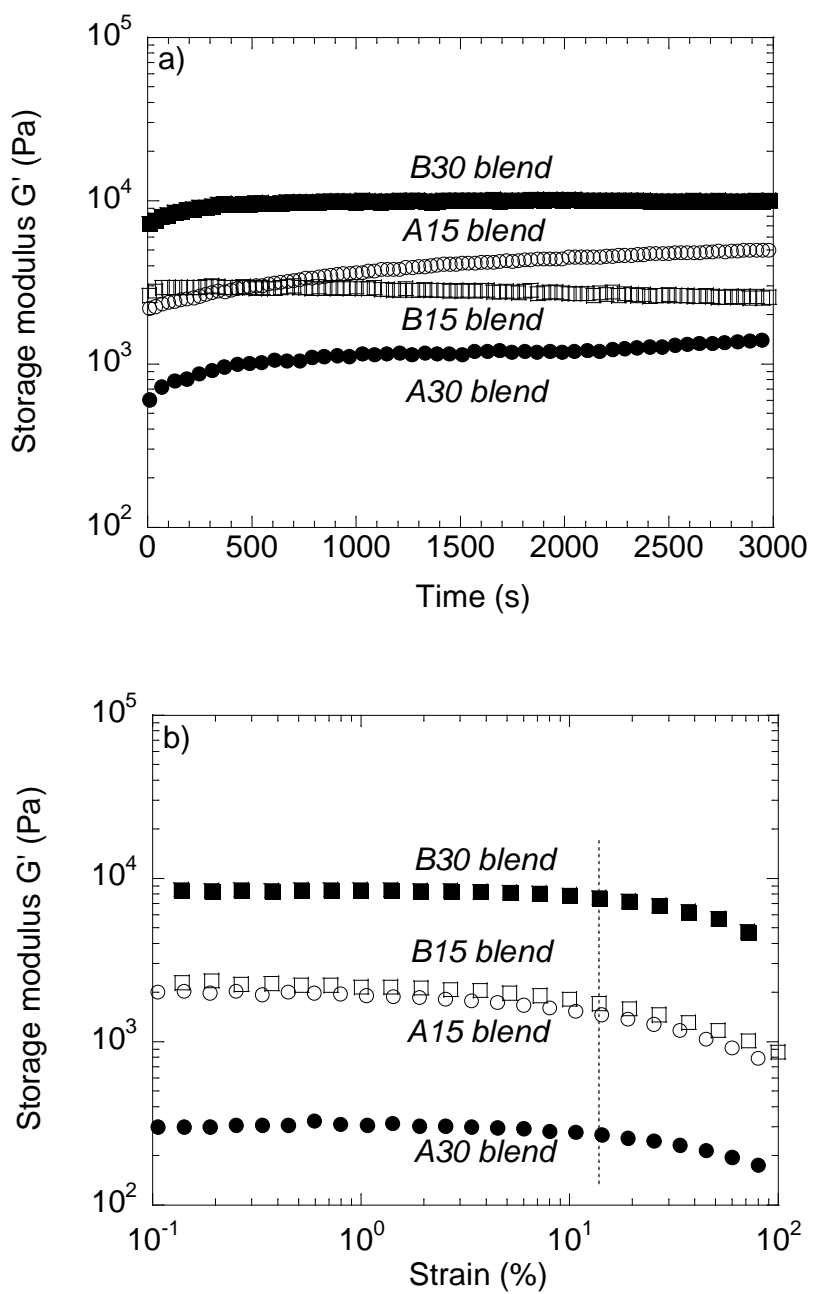

Figure 7. Démé et al. 

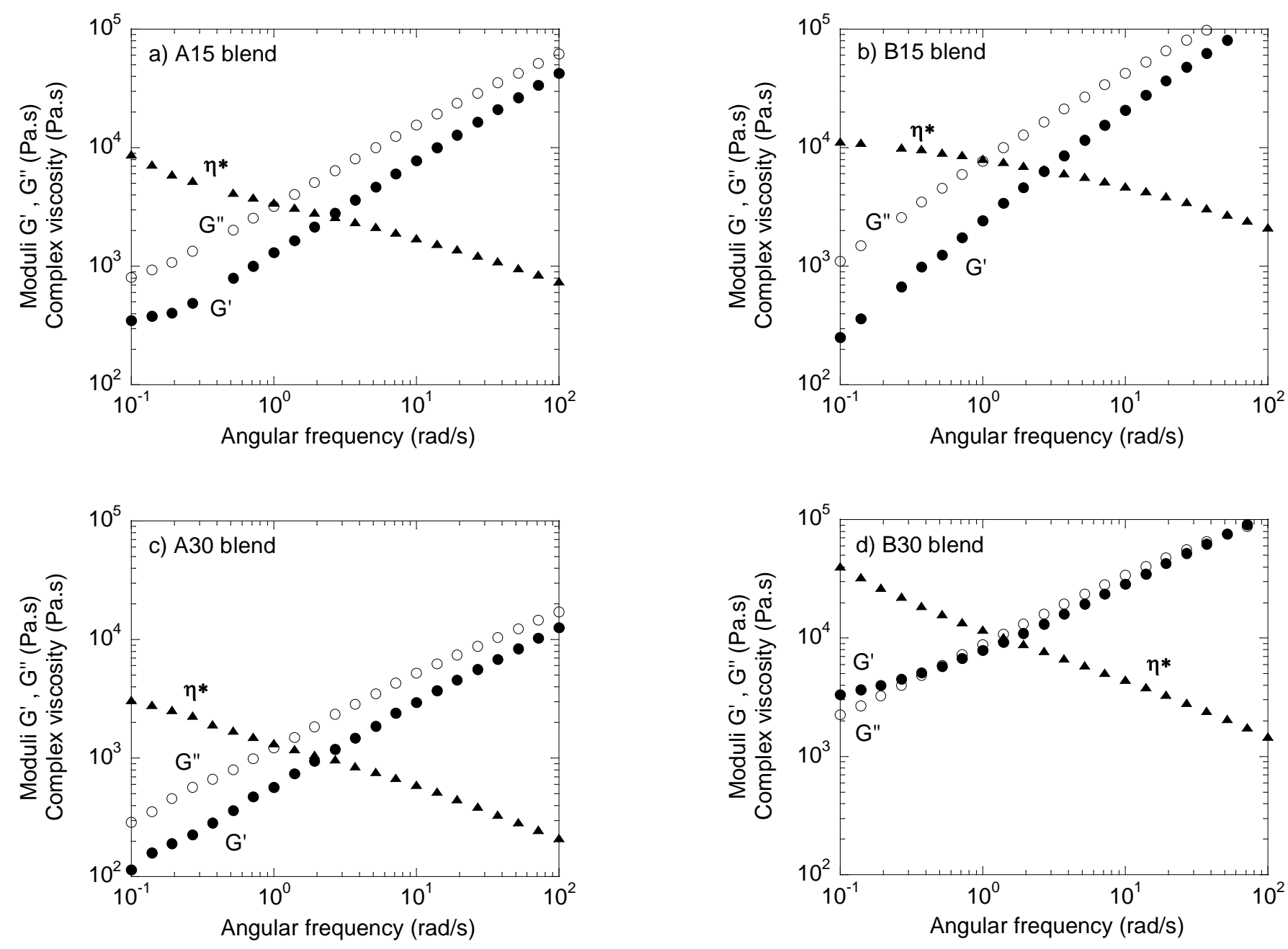

Figure 8. Démé et al. 

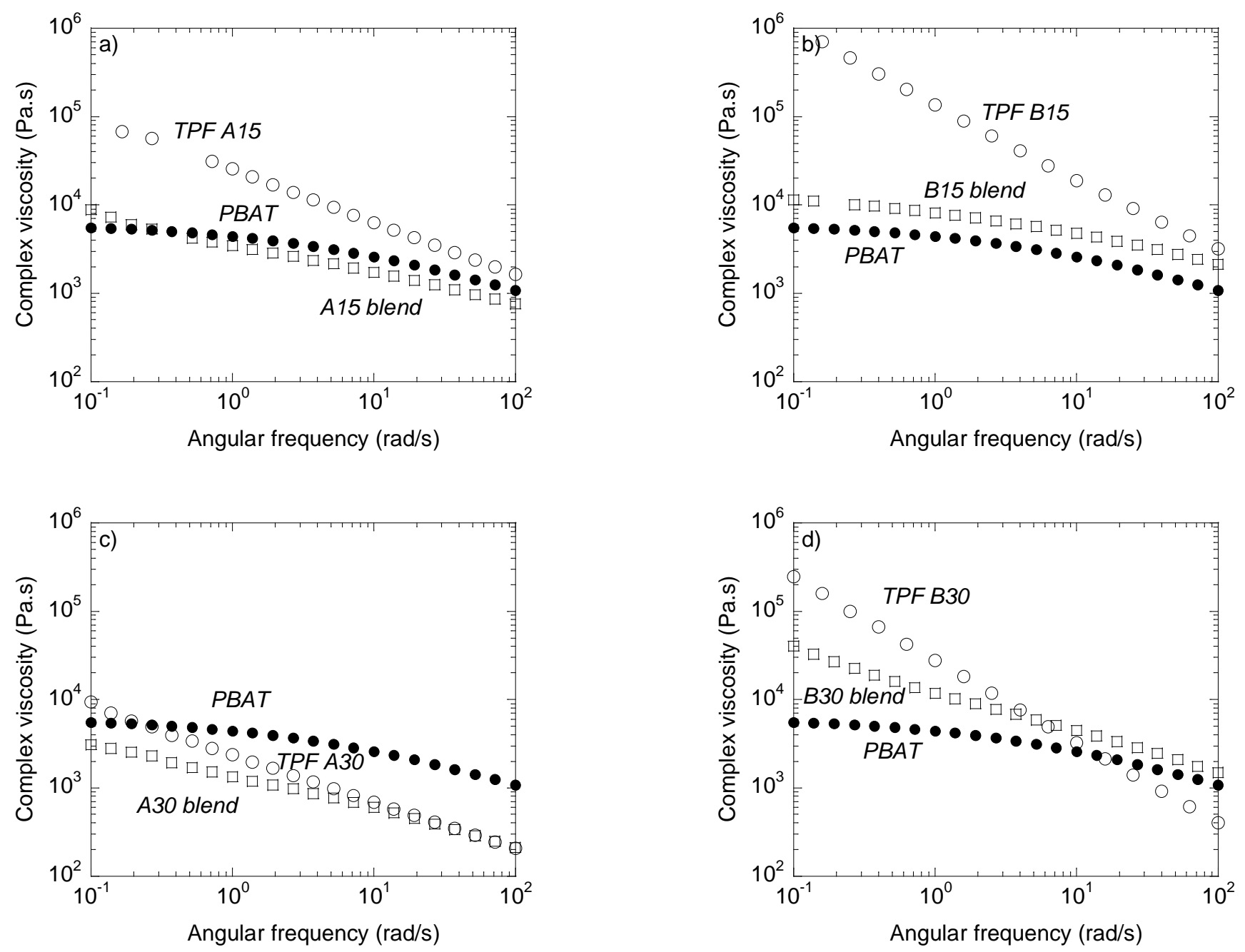

Figure 9. Démé et al. 

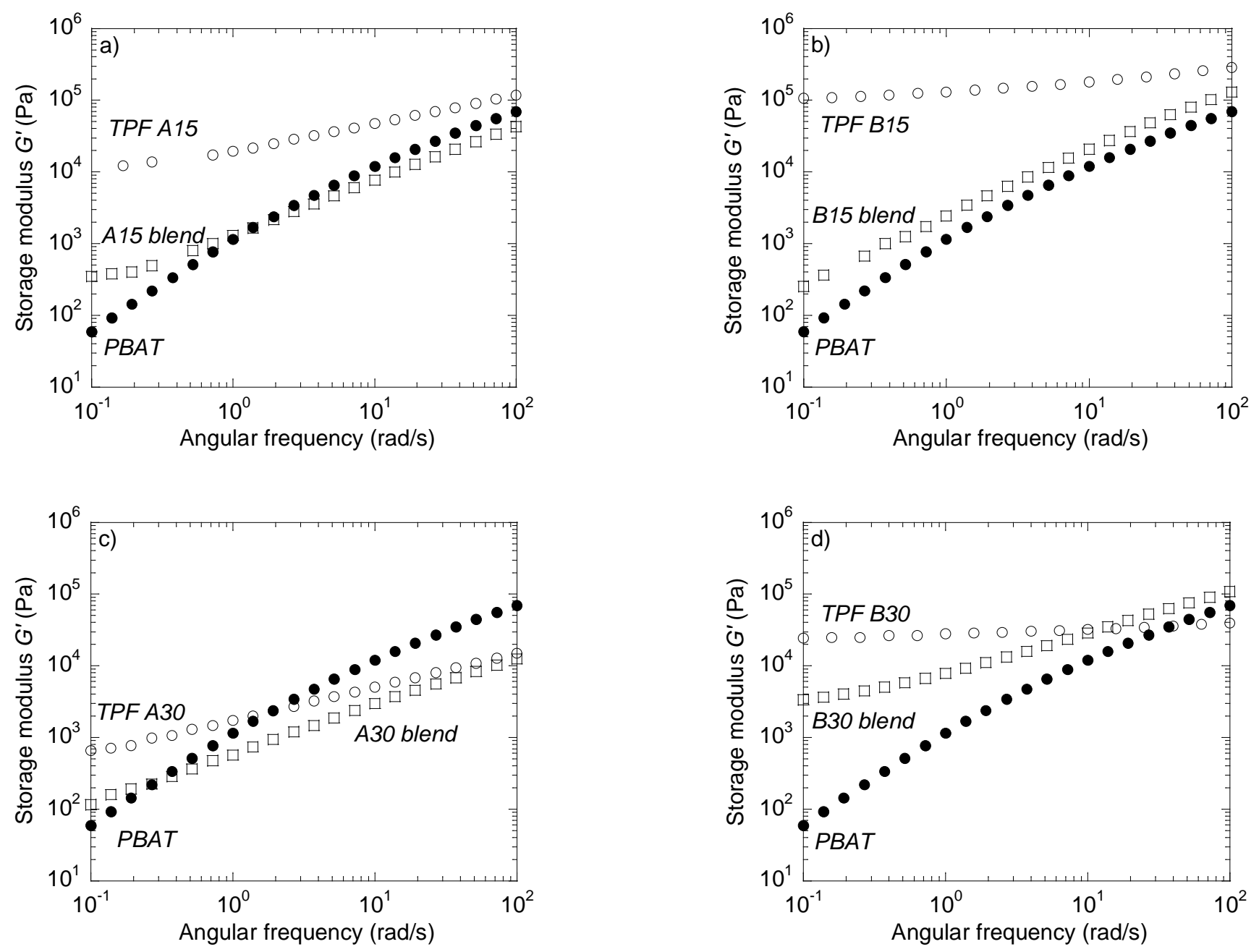

Figure 10. Démé et al. 

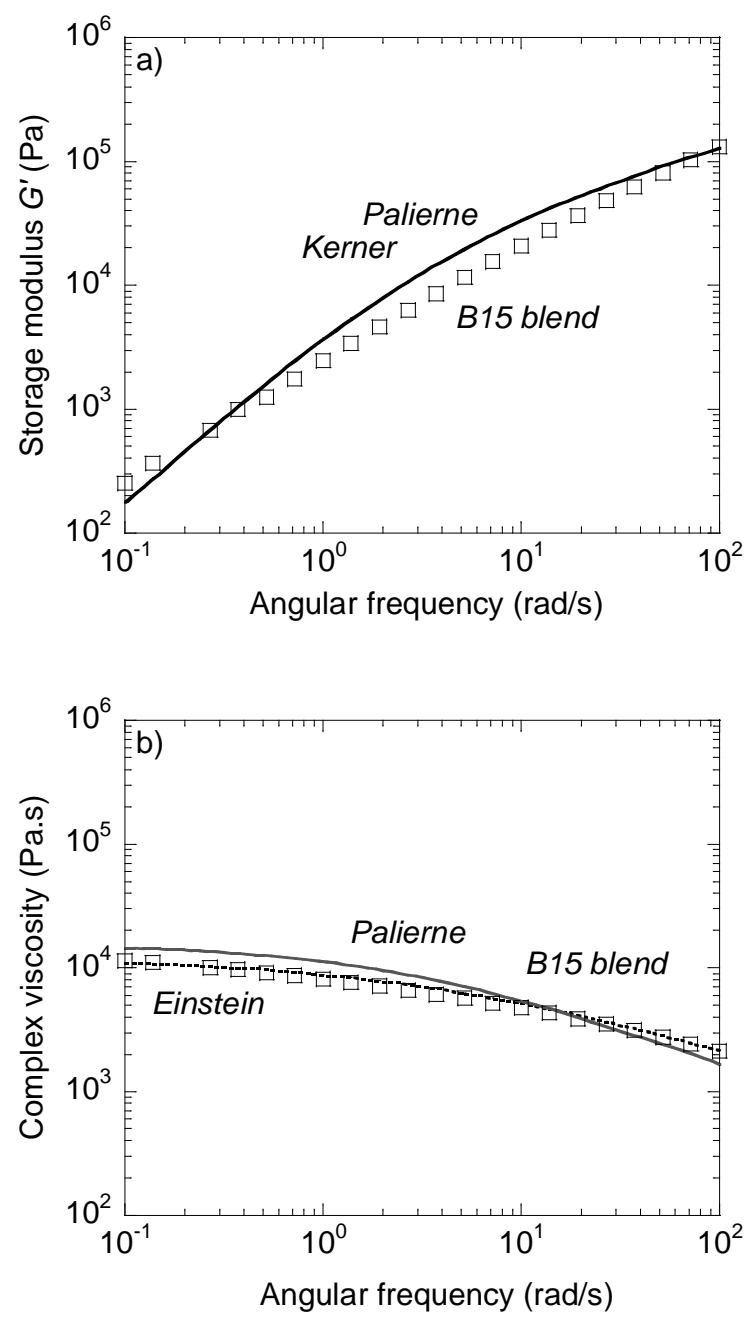

Figure 11. Démé et al. 